\title{
Family Reunification Decision-Making in Dutch Family Foster Care: A Dual Perspective Approach
}

\author{
Mirte S. L. Teunissen ${ }^{1} \cdot$ Anouk Goemans $^{1}$ (D) - Frank van Holen ${ }^{2} \cdot$ Johan Vanderfaeillie $^{2}$. \\ Harold T. Nefs ${ }^{1} \cdot$ Huub M. Pijnenburg ${ }^{3} \cdot$ Harm Damen $^{4} \cdot$ Paul H. Vedder ${ }^{1}$
}

Published online: 27 August 2020

(C) The Author(s) 2020

\begin{abstract}
Background An important responsibility of the child welfare system, is taking decisions on the reunification of children with their birth parents after the children have lived in foster families. We currently lack evidence-based knowledge to guide the reunification decision-making process.

Objective The present study uses concept mapping as an exploratory method, to identify themes that seem to be used by two groups of professionals in their judgement and decision making on reunification.

Method First, we consulted 78 foster care workers and studied 172 legal cases to examine criteria important for reunification. Next, unique criteria were grouped and rated by 35 foster care workers and also by 12 family judges separately. The data was analysed with multidimensional scaling and cluster analysis which resulted in a concept map for each group of professionals.

Results Both foster care workers and family judges suggested the following themes in the reunification decision-making process: (a) birth parents' functioning and parenting abilities, (b) birth parents' acceptance of support, and (c) the child's functioning, developmental needs and wishes. Besides parallel themes, both foster care workers and family judges also seem to consider unique themes.

Conclusions The suggested similarities and differences between the two groups of professionals possibly reflect different professional frameworks. The foster care workers' considerations seem to have an orientation towards permanency planning while the family judges' considerations seem to be linked to the legal framework. Gaining insight in the perspective of different groups of professionals involved in the process of reunification, is a small but important step towards reaching consensus through discussion in order to achieve the optimal implementation of the decisions considered in the best interest of children's future.
\end{abstract}

Keywords Decision-making · Family reunification · Out-of-home placement $\cdot$ Family foster care $\cdot$ Juvenile court . Child welfare

Anouk Goemans

a.goemans@fsw.leidenuniv.nl

Extended author information available on the last page of the article 
In the Netherlands, over a period of 6 years approximately $20 \%$ of children in family foster care are reunified with their birth parents (Goemans et al. 2016). The decision for family reunification is made in a process called permanency planning. In the Netherlands, permanency planning is a lengthy and less definitive process than for example in the US (Vedder et al. 2015). Foster care in the Netherlands can either be short-term or long-term. Shortterm foster care is considered an intervention aimed at family reunification, while longterm foster care is considered a more permanent living arrangement in the foster family (Goemans et al. 2016). However, the option for either type of foster care can be evaluated repeatedly over time. During the process of permanency planning, different groups of professionals are involved such as a guardian, foster care workers and a child psychologist. Guided by the outcome of permanency planning, the guardian can request a juvenile court to terminate the placement in care (art. 1:265d lid $1 \mathrm{BW}$ ). If this request is granted by a family judge, the child is reunified with its birth parents.

The decision to reunite is complex, because it involves potential risks that can have long-term damaging implications for both the child and families concerned (Arad-Davidzon and Benbenishty 2008; Wade and Biehal 2011). Up to $65 \%$ of reunited children reenter care within 5 years and subsequent reunifications remain problematic (Farmer and Lutman 2012). Moreover, the proportion of maltreatment recurrence is high, with proportions varying between 30 and 85\% (Connell et al. 2009; Farmer 2012; Fuller 2005). Failed reunifications and maltreatment are related to serious psychological problems during childhood and and with psychiatric disorders, drug abuse and suicide attempts later in life (Norman et al. 2012).

Because the reunification decision affects the safety and well-being of a child, it is important to use well-validated decision-making models. A major concern in child welfare though, is the lack of evidence-based decision-making models (Bartelink et al. 2015; Goemans et al. 2016; Vedder et al. 2015; Vial et al. 2020). However, important steps have been made. Studies have identified some criteria associated with the decision to reunite the child with their birth parents (Courtney 1994; Goemans et al. 2016; López et al. 2013; Sinclair et al. 2007) whereas other studies identified predictors of (un)successful reunification (Becker et al. 2007; Farmer 2012; Wade and Biehal 2011). For two reasons unfortunately, these findings cannot be easily translated into evidence-based models for decision-making. Firstly, it is unclear which criteria are currently used in decision-making practices. Secondly, part of the criteria or predictors found in the earlier studies are of a "non-dynamic" type (e.g., household structure, age of the child, and gender). Although these stationary criteria are valuable to inform the type of intervention that is suitable for a family, these stationary criteria are less likely to be used as targets or goals in intervention. Therefore, it is less likely that these "non-dynamic" criteria are evaluated and judged in current decision-making practices.

The current study aims to uncover criteria that are used in the decision-making for reunification according to foster care workers and family judges from juvenile court. Assessing the perspectives of the two groups of professionals separately, will broaden the scope of dynamic and currently applied criteria. Moreover, comparing the perspectives of foster care workers to that of family judges is important because it is in the child's best interest that foster care workers and family judges gain insight into the criteria used by other parties involved. Insight into the reasoning or ruling for reunification by different involved parties can be helpful for systematic decision-making. Child welfare decisions are often based on dialogues between different groups of professionals. Dialogues that immediately lead to alignment may be at least as productive as disagreement between the groups of professionals, since the different professionals base their perspective on their own expertise and 
experience. However, it is likely beneficial for the implementation of the decision when the dialogue between different groups of professionals eventually leads to consensus. In the Netherlands, where the current study is conducted, there is likely a lack of alignment in the use of criteria between parties that are involved in the process of reunification, which can lead to mutual frustration and can impair constructive communication between parties (Vedder et al. 2015). Therefore, the current study aims to increase the knowledge required to effectively support and create evidence-based decision-making models usable in policy and practice on family reunification, by assessing and comparing the criteria used by foster care workers and family judges.

\section{The Role and Perspective of Foster Care Workers}

In the contexts of the reunification process, the Dutch Family Council emphasised that the development, functioning and wishes of the child should be considered (2001). Foster care workers are in a particularly good position to provide family judges valuable information about the well-being and development of the child in the foster family, as well as about contacts between the child and its birth parents (Daamen 2014). In the Netherlands however, foster care workers do not directly report to family judges when decisions for reunification are to be made. Although foster care workers are part of a process called permanency planning, which outcome can result in a request for reunification, the guardian decides which information received from foster care workers is sent to juvenile court. This indirect way of communicating between foster care workers and family judges might be problematic. Information may get lost on its way, because foster care workers and guardians do not necessarily share the same vision (Farmer 2012; Vedder et al. 2015). Research findings regarding the focus in the reunification process by the child's guardian inconsistently suggest that the focus is mostly on the birth parents' functioning and improvement of their parenting abilities (Arad-Davidzon and Benbenishty 2008; Dankaart 2011), or that the focus is mostly on the child's functioning (Vanderfaeillie et al. 2017).

One of the aims of the current study is to find out what foster care workers consider necessary for reunification. It is expected that they would formulate criteria for reunification akin to the themes that are considered relevant in permanency planning. Particularly, foster care workers are in a position to provide valuable information about the wellbeing and development of the child in the foster family, as well as about contacts between the child and birth parents (Daamen 2014; Schofield 2005; Tilbury and Osmond 2006). Furthermore, aiming to improve the caregiver-child relationship, intervention strategies can be instituted. For instance, when parenting practices and improving parent's abilities and their willingness to cooperate are goals of the intervention, the effects are likely to be evaluated when considering family reunification (Dawson and Berry 2002; Tilbury and Osmond 2006; Vischer et al. 2017).

\section{The Role and Perspective of Family Judges}

Finding out about what foster care workers deem relevant, is not the only hurdle to take when optimising decision making is at stake. To date, examining the justification of the court decision in civil law has to the best of our knowledge, been done in only one study worldwide: Vogels (2009) reported that improvement in birth parents' functioning and 
ability to satisfy their child's basic needs were often mentioned to argue in favour of family reunification in the Netherlands. Vogels (2009) also noticed that the child's functioning and wishes were hardly considered in the decision process. It is important to realise that the Vogels' study included only six court cases. Examination of more cases would provide a more representative and more comprehensive overview of the judicial justification of decisions regarding reunification. This is a second aim of the current study. It is expected that family judges would consider specific laws in the Dutch Civil Code or Burgerlijk Wetboek (BW), the Convention on the Rights of the Child (1989) and the European Court of Human Rights' (2019) in their rulings regarding reunification. Considering the Dutch Civil Code, family judges have to decide whether the development of the child is still endangered (art. 1:255 BW), what the abilities of the parents are (art. 1:265d BW), and whether parents are cooperative (art. 1:255 lid $2 \mathrm{BW}$ ). The paramount purpose of all of this is to arrive at a decision that is in the best interest of the child (art. 1:265d BW). Towards this decision, several rights of the international Convention on the Rights of the Child (1989) may be considered as well, such as the right to life, survival and development (art. 6) and the right to express his or her views freely (art. 12). Other considerations that are likely considered, are the rights, duties and interest of other parties, especially the right to family life of both the birth parents and foster parents (European Court of Human Rights, 2019, art. 8). The legal decision should always be justified by arguments that clarify how the child's interests have been weighed against other considerations, while also taking into account the child's current safety and future risk of the decision (Committee on the Right of the Children 2013).

A third aim is to compare the clusters between foster care workers and family judges in order to find out how well aligned those are, and with which clusters and criteria the respective perspectives could be enriched. It is hypothesised that there are differences in the perspectives of the two groups of professionals regarding what is considered relevant in decision-making (Britner and Mossler 2002). Clarifying the similarities and differences in the criteria that are considered relevant by foster care workers and family judges will increase the knowledge necessary for facilitating evidence-based family reunification policies and practices. A better insight in the similarities and differences in the use of criteria between foster care workers and family judges may also help reach consensus between these two groups, which is considered relevant for decisions on reunification and their implementation.

\section{Current Study}

The main research question is: To what extent are the clusters of information that foster care workers consider relevant for reunification comparable to the clusters of information that family judges consider relevant in their reunification decision after placement in foster care? To answer this question, we formulated two sub-questions: What criteria do foster care workers consider relevant in reunification decision making, and what are the criteria that family judges consider relevant when reunification is at stake. It was hypothesised that both foster care workers and family judges, consider the following four clusters of information based on research regarding permanency planning and previously discussed laws:

1. birth parents' functioning and parenting abilities (art. 1:255 lid 1 part b BW; art. 1:265b lid 1 BW; Tilbury and Osmond 2006); 
2. birth parents' acceptance of support (art. 1:255 lid 1 part a BW; Dawson and Berry 2002);

3. birth parent-child relationship (art. 8 'the right to respect for private and family life' in European Court of Human Rights 2019; Tilbury and Osmond 2006);

4. child's functioning, developmental needs and wishes (art. 1:255 lid $1 \mathrm{BW}$; art. 1:265d BW; art. 6 'the right to life, survival and development' and 12 'the right to express views freely' in Convention of the Rights of the Child 1989; Tilbury and Osmond 2006; Schofield 2005).

In addition to these four clusters of information, it was hypothesised that family judges consider a unique fifth cluster: the foster parent-child relationship (art. 8 in the European Court of Human Rights, 2019). In any decision regarding the best interest of the child, family judges must consider the child's current wellbeing, which is also influenced by the current relation with their foster parents. Perhaps surprisingly, this may be somewhat different for foster care professionals who, during decision-making specifically on reunification and not permanency planning in general, appear more likely to focus predominantly on the "good enough" question of whether birth parents can be expected to provide a safe environment for a child to grow up, rather than on the question of which family can provide the best care of the child: birth or foster family (NVO, BPSW and NIP, 2015a).

Moreover, it was hypothesised that there is a difference between the two groups of professionals regarding the importance attributed to the clusters of information (Britner and Mossler 2002). Based on earlier studies, it was hypothesised that foster care workers regard the birth parent-child relationship most important (Tilbury and Osmond 2006), whereas family judges deem birth parents' functioning and parenting abilities most important (Vogels 2009).

\section{Method}

We performed two separate studies that were approved by the Review board of Education and Child Studies at Leiden University. In study 1 we assessed the criteria considered relevant by foster care workers for reunification. In study 2 we assessed the criteria considered relevant by family judges, when reunification is under consideration. Each study consisted of two phases. The goal of the first phase was to create a list of unique criteria that are considered necessary for reunification. The goal of the second phase was to create clusters of information based on the list of unique criteria. In line with earlier studies (e.g. Brown 2008; Van Holen et al. 2019), data from the second phase were analyzed using concept mapping (Trochim 1989).

\section{Participants Study 1}

In the first phase of the study, three out of 28 Dutch foster care agencies were invited. All three agencies agreed to participate, each consisting of several foster care teams. Team meetings were organised for a total of six foster care teams. There were no participant inclusion or exclusion criteria other than being part of the team. All team members took part in the team meetings. This resulted in a convenience sample of 78 participating foster care workers. Table 1 presents demographics. Most participants held either a bachelor's degree in Social Work (75.6\%) or a master's degree in Education and Child Studies 
Table 1 Demographics of the foster care worker

\begin{tabular}{|c|c|c|c|c|c|c|}
\hline \multirow[t]{2}{*}{ Variables } & \multicolumn{2}{|c|}{$\begin{array}{l}\text { Phase } 1 \\
(N=78)\end{array}$} & \multicolumn{2}{|c|}{$\begin{array}{l}\text { Phase } 2 \\
(N=35)\end{array}$} & \multirow[t]{2}{*}{$t$ test $/ \chi^{2}$ test $^{\mathrm{d}}$} & \multirow[t]{2}{*}{$p$} \\
\hline & $M / \%$ & $S D$ & $M / \%$ & $S D$ & & \\
\hline Age in years & 41.6 & 10.2 & 42 & 9.2 & $t(34)=.24$ & .812 \\
\hline Experience in years & 8.7 & 8.2 & 7.7 & 8.3 & $t(34)=-.18$ & .856 \\
\hline Gender $^{\mathrm{a}}(\%)$ & $91 \%$ & & $88.6 \%$ & & $\chi^{2}(1)=.26$ & .611 \\
\hline Education $^{\mathrm{b}}(\%)$ & $75.6 \%$ & & $65.7 \%$ & & $\chi^{2}(1)=1.87$ & .171 \\
\hline Profession $^{\mathrm{c}}(\%)$ & $91 \%$ & & $85.7 \%$ & & $\chi^{2}(1)=1.21$ & .272 \\
\hline
\end{tabular}

${ }^{\mathrm{a}} \mathrm{Female}$ (male)

${ }^{\mathrm{b}}$ Social Work Bachelor (Non-social Work Bachelor)

${ }^{\mathrm{c}}$ Social worker (child psychologist)

${ }^{\mathrm{d}}$ The one samples t-test and nonparametric Chi-Square Test were used to check the difference between the participants in phase 1 to the participants in phase 2 to the participants in phase 1 for all the listed variables

(21.8\%); a few participants completed senior vocational high school (2.6\%). Most participants worked as social workers (91\%) and a minority as child psychologists (9\%).

In the second phase of the study all 77 participants from the first phase (one had meanwhile quit her job) were asked to complete an online survey. A total of 50 participants (64.9\%) started the survey; which was completed by 35 participants (45.5\%). Attrition proved unrelated to age, years of working experience, gender, education or profession (see Table 1).

\section{Participants Study 2}

In the first phase of the study, information from published and unpublished legal cases were collected. This information consisted of case characteristics and the arguments used by family judges for their ruling. Two sources were used to retrieve a representative sample of legal cases: three Dutch courts and two online repositories (viz. the website 'Legal Intelligence' and the website 'Dutch jurisdiction' or 'de Rechtspraak'). We took three steps for the inclusion of legal cases.

In the first step, we used search terms that refer to specific laws in Civil Code, which are 'BW 265d'; 'discontinue placement in care'; '1:265i BW'; '1:265C BW'; '1:265b foster care permanency'. In the second step, cases were excluded when a statement about outof-home placement was absent in the abstract. In the third step, we used the following five inclusion criteria, which all had to be met: (1) the plaintiff or defendant explicitly asked for family reunification; (2) the reunification request was judged admissible by the court; (3) during the out-of-home placement the child lived in a foster family; (4) the case was ruled in the Netherlands; and, (5) the year of ruling was post 2011. This process led to an inclusion of 172 cases. To verify that the cases from the two sources could be analysed together, potential predictors of reunification found in previous studies were compared (Courtney 1994; López et al. 2013; Sinclair et al. 2007). No differences were found. On average, the children in the included cases were 6.5 years old $(S D=3.9)$, spent on average 21.2 months in foster care $(S D=17.4)$ and spent on average 17.1 months in the current foster family 
$(S D=15.7)$. Furthermore, most of the birth parents were divorced $(75 \%)$, almost a quarter had a relationship (22\%) and a few were widowed (3\%).

The second phase of the study consisted of interviews with family judges. Family judges were invited from four out of eleven Dutch courts. All 12 invited family judges (10 female) were willing to participate, which resulted in a convenience sample. All family judges held a master's degree in law. Their average age was $51.6(S D=8.7)$, and on average they had 10.8 years of experience as family judge $(S D=6.1)$.

\section{Materials and Procedure Study 1}

The first phase of the study, the team meeting, took $45 \mathrm{~min}$. Two research assistants participated. They were master students from Education and Child Studies and strictly followed a study protocol. First, participants filled out a written informed consent form. Next, each answered in writing the open question "which criteria do you consider for reunification after placement in foster care". Based on the 661 answers, unique criteria were selected by four of the authors (MT, AG, $\mathrm{FvH}, \mathrm{JV})$ using the inter-rater agreement process described by Brown (2008). Two independent pairs of raters made a list of criteria and the two lists were then crosswise compared by the two pairs of raters. Full between-pairs consensus was achieved through discussion, resulting in a unique list of 53 criteria.

The second phase of the study which was the online survey, took $45 \mathrm{~min}$. Participants were asked to group all unique criteria (53) they thought conceptually belonged together. In this task, participants were free in the number of groups they created, with two restrictions: (1) each criterion could only be placed in one group, and (2) the number of groups had to be more than one and less than the number of criteria. After the grouping task, participants rated each criterion on a 7-point Likert scale regarding its importance for reunification, from completely unimportant (1) to very important (7).

\section{Materials and Procedure Study 2}

In the first phase of the study, legal cases were encoded independently by six research assistants, all bachelor or master students of Education and Child Studies. A coding system was developed, based on consultation of a jurist who had experience with coding legal cases. The coding system incorporated case characteristics (e.g. the lawsuit, the plaintiff and age of the child) and the argumentation of the family judges' ruling. The research assistants received a coding training from the first author. To assess interrater reliability, $10 \%(n=17)$ of the cases were randomly selected and double coded independently. The agreement percentage was $79.3 \%$. All instances of between coder differences were discussed, resulting in $100 \%$ coding consensus. During the coding process, all criteria that family judges used were subsequently entered in a list. Coding of the last thirty cases yielded only one new criterion. This was taken as an indication of saturation. Coding all 172 cases thus led to an initial list of 259 criteria. Unique criteria were selected by three authors (MT, AG, JV) using the inter-rater agreement process described by Brown (2008). This agreement process resulted in a final list of 76 unique criteria.

In the second phase of the study, family judges were asked to partake in a face to face standardised structured interview with the first author, which took about $60 \mathrm{~min}$ after they gave written informed consent. The procedure was similar to the one used with the foster care workers in Study 1. 


\section{Data Analyses}

The data-analyses consisted of four successive steps, using data from the second phase of the studies to investigate the clusters of information foster care workers and family judges consider in family reunification. These steps were based on concept mapping (Trochim 1989) and executed for foster care workers (study 1) and family judges (study 2) separately.

In the first step, we created a combined group similarity matrix to prepare the data for performing the non-metric multidimensional scaling (MDS) analysis.

In the second step, the information in the combined group similarity matrix was translated into a two-dimensional solution that was presented in a point map using non-metric multidimensional scaling (Kruskal and Wish 1978). The reason for a two-dimensional solution is that it is better interpretable and more useful than a solution with more than two dimensions, especially when coupled with cluster analysis (Kruskal and Wish 1978). The MDS solution fit to the original data was summarised using two indicators: R-squared $\left(R^{2}\right)$ and the Kruskal Stress Index. A $R^{2}$ value greater than .60 is considered acceptable (Jaworska and Chupetlovska-Anastasova 2009) and Kruskal Stress values smaller than or equal to .05 are excellent, values from .10 to .05 are good, values from .20 to .10 reasonable, and values greater than .20 are bad (Giguère 2006).

In the third step, the point-map was partitioned into clusters using a hierarchical cluster analysis (Everitt 1980). In order to decide the number of clusters, the dendrogram, fit statistics, and conceptual fit were examined. For the fit statistics, a high Calinski-Harabasz Index (CH-Index) represents a better solution than a cluster with a lower $\mathrm{CH}$-Index. Moreover, the Sum of Squares Within (SSW) score represent a standard for the unexplained variance. An optimum SSW score is indicated with the scree criterion and is visualised in a plot.

As a fourth step, the standardized bridging value of each criterion was calculated to help label the clusters. This standardized value is called the bridging index. A bridging index ranges between .0 and 1.0, where a criterium with a lower bridging index is generally a better indicator of the meaning of a cluster than a criterium with a higher bridging index (Trochim 1987). The derived clusters of information for foster care workers and family judges were compared qualitatively. First, we focused on the content of the clusters, and then on the ratings of the importance. The comparisons were made using absolute numbers. Similarities and differences were not tested for significance and the results should therefore be interpreted with caution.

\section{Results}

\section{Study 1}

For the study of foster care workers, the combined group similarity matrix is translated into non-metric multidimensional scaling solution (step 1). The fit of the multidimensional scaling solution seems to be reasonable, indicated by both the Kruskal Stress Index of .18 and the $R^{2}$ of .77 (step 2). Then, the multidimensional scaling solution is partitioned into clusters using a hierarchical cluster analysis. The dendrogram of the hierarchical cluster analyses suggests a three-, five- and seven-cluster solution. The $\mathrm{CH}-\mathrm{Index}$ also supports a three- and a seven-cluster solution, while the SSW plot shows the scree criterion at threecluster solution (see "Appendix 1"). Moreover, a three-cluster solution could explain about 
$80 \%$ of the variance in the data, while a five-cluster solution explains $88.4 \%$, and a sevencluster solution $93.3 \%$. Looking for both optimal statistical and conceptual fit, we opted for a seven-cluster solution (step 3). The seven clusters of information were labelled as follows after obtaining the bridging indexes (step 4): secure birth parent-child relationship, readiness of the family, preparation and timing adapted to the child, birth parents' functioning and parenting skills, formal and informal support, readiness and child's wishes, and the continuation of cooperation by birth parents. The seven-cluster solution is visualised in the concept map in Fig. 1; the criteria are listed in "Appendix 2".

\section{Study 2}

For the study of family judges, the combined group similarity matrix is translated into nonmetric multidimensional scaling solution (step 1). The fit statistics of the MDS solution, the $R^{2}$ of .68, suggested a good fit, while the Kruskal Stress Index of 22.4 suggested a problematic fit. Therefore, caution in interpreting the results is warranted (step 2). Then, the multidimensional scaling solution is partitioned with hierarchical cluster analyses that gave different cluster solutions. The hierarchical cluster analyses gave different cluster solutions. The dendrogram supported a three-, five-, and six-cluster solution. The $\mathrm{CH}$-Index suggested a

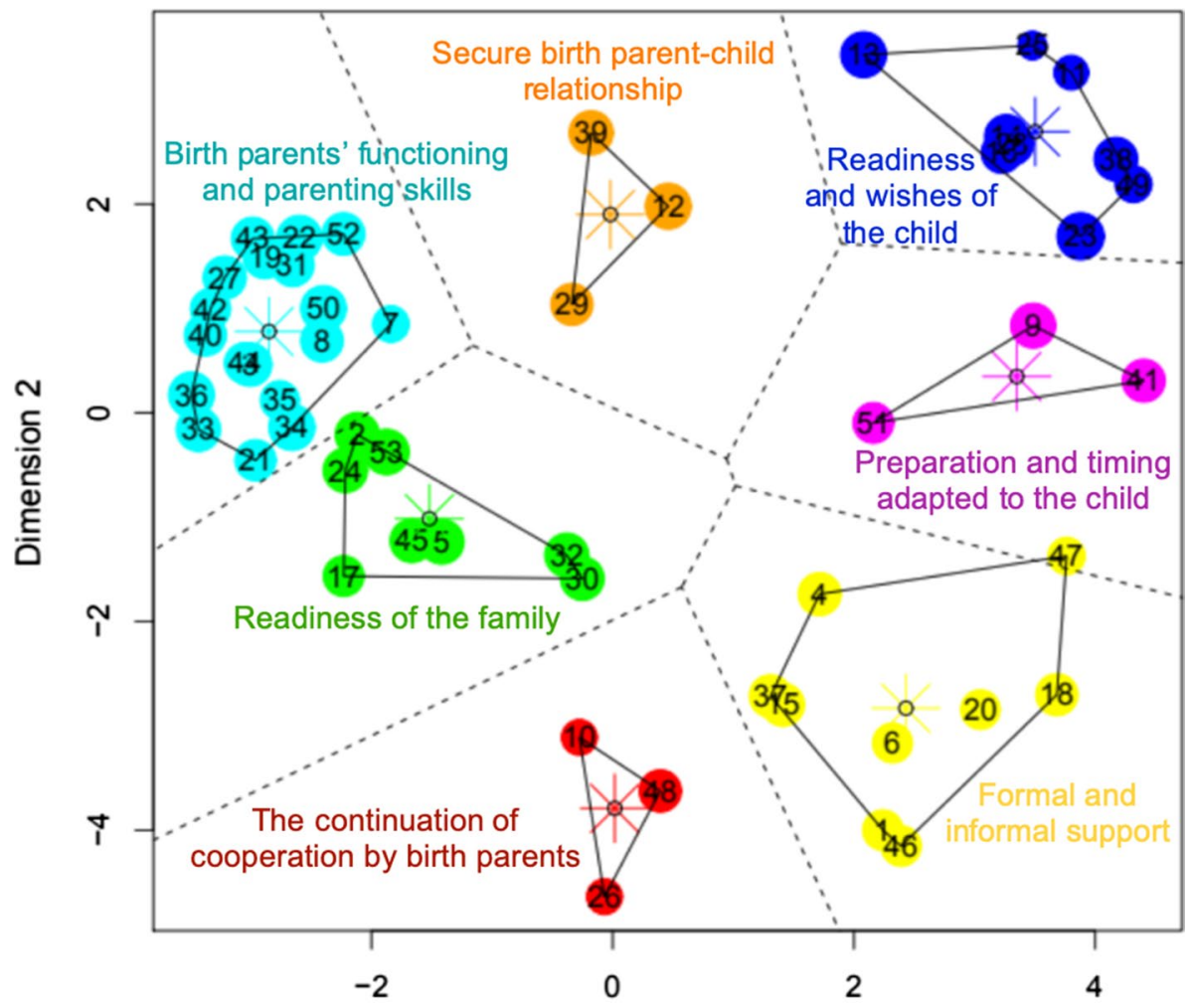

Dimension 1

Fig. 1 Concept map of 53 clustered criteria foster care workers consider relevant for reunification 
six-cluster solution while the SSW plot did not differentiate between these three solutions (see "Appendix 3"). Therefore, we opted for the six-cluster solution (step 3). The six clusters of information were labelled as follows after obtaining the bridging indexes (step 4): birth parents' functioning and parenting skills, readiness of the child, safety and the continuation of cooperation by birth parents, formal and informal support, the child's functioning and wishes, and foster parent-child relationship. The six clusters of information are visualised in the concept map in Fig. 2; all represented criteria are listed in "Appendix 4".

\section{Comparing Study 1 to Study 2}

The deduced clusters of information from both studies were compared qualitatively. We found four overlapping clusters of information, three unique clusters for foster care workers and one unique cluster for family judges (see Table 2). The four overlapping clusters concern the following: (1) birth parents' functioning and parenting skills; (2) formal and informal support; (3) the continuation of cooperation by birth parents; (4) readiness and wishes of the child. The three unique clusters of information for foster care workers are: (1) secure birth parent-child relationship; (2) readiness of the family; and, (3) preparation and timing adapted to the child. One cluster was found to be unique for family judges, that was the foster parent-child

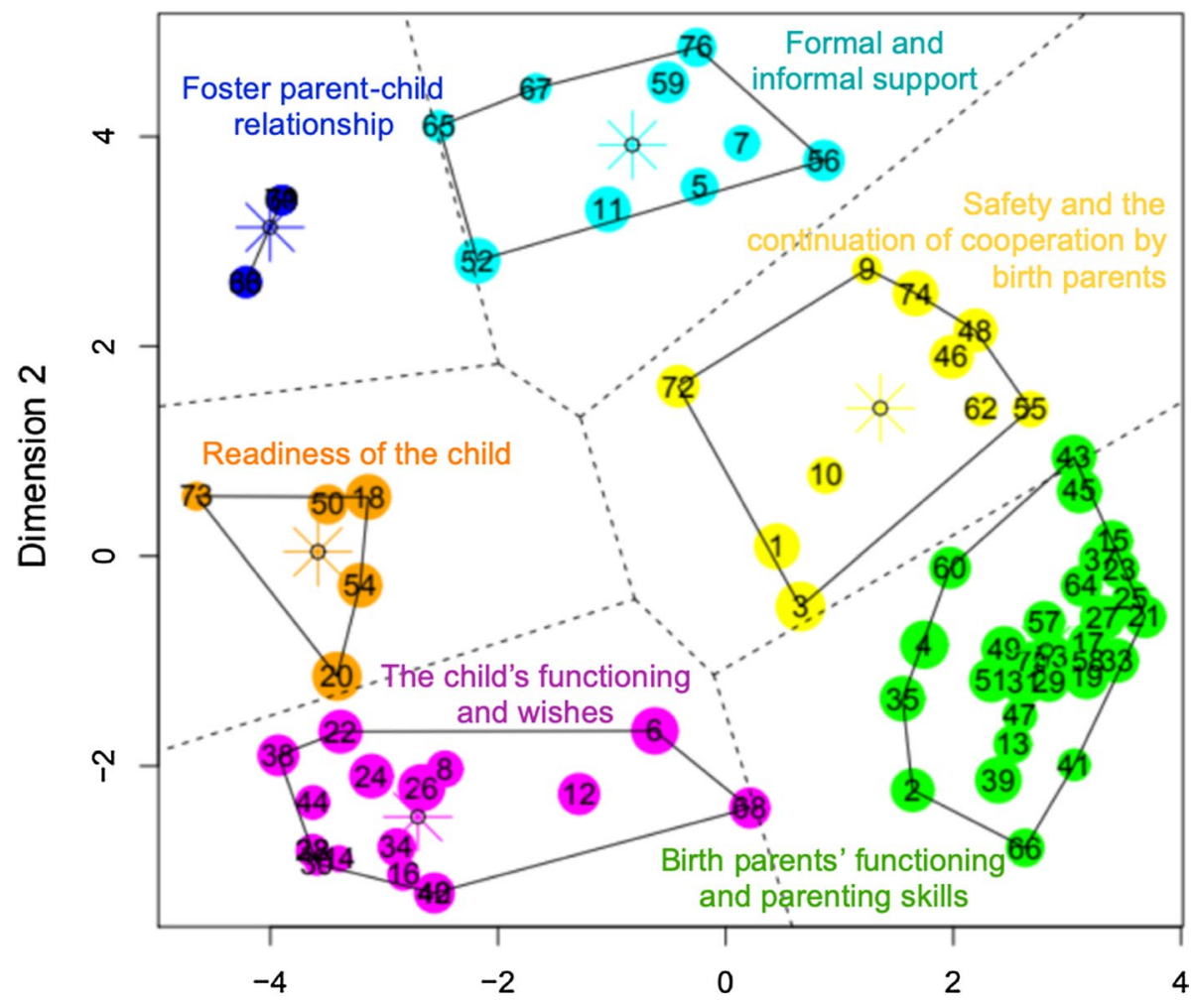

Dimension 1

Fig. 2 Concept map of 76 clustered criteria considered relevant by family judges in deciding on reunification 


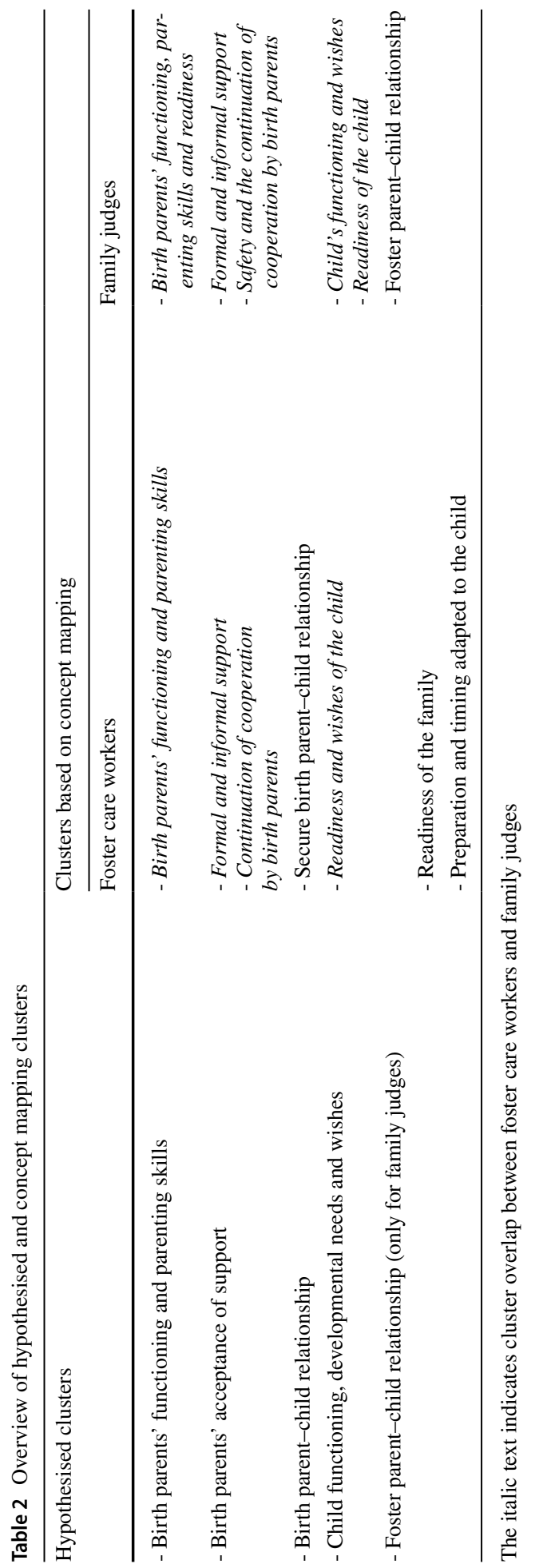


relationship. Moreover, regarding the clusters' rated importance, foster care workers consider a secure birth parent-child relationship $(M=6.37, S D=.75)$ most important, while family judges consider birth parent's functioning and parenting skills $(M=5.83, S D=.55)$ to be most important. Although there appear to be differences between the perspectives, it is important to note that the range of importance scores for the various clusters were narrow, and no significance testing of differences between the two groups of professionals had been performed.

\section{Discussion}

To answer the research question to what extent the clusters of information that foster care workers consider relevant for reunification are comparable to the clusters of information that family judges consider relevant in their reunification decision after placement in foster care, we compared the clusters identified by both groups. Before we discuss the results in more detail and how they correspond with our hypotheses, we first present some of the limitations of our study which are important to keep in mind during the discussion of our results.

\section{Limitations}

The first limitation is that the selection of the participants in both Study 1 and 2 resulted in small size non-random samples, especially in the second phase of the studies. It is important to note that in absolute terms, interviewing 12 family judges is indeed a small number, which may negatively impact the validity of the results. However, in relative terms we estimate to have interviewed $10-20 \%$ of the family judges currently working in the Netherlands. Nonetheless, we have no clarity about representativeness of the results. This warrants caution when interpreting the results.

Another limitation was the timing of validation of the list of criteria used by family judges. This list was validated during the interview phase by asking whether it was deemed correct and complete. Preferably this validation would have preceded the interview phase. Because of this suboptimal timing we were not able to incorporate the feedback of the family judges in the list of criteria. We recommend that future studies incorporate calibration in the list of criteria of family judges found in "Appendix 5".

Furthermore, another limitation was that the methods of Study 1 and 2 were not identical, which hindered the comparability of the two studies. In phase 1 there was a difference in type of informants. We consulted foster care workers and studied legal cases instead of consulting family judges. Due to the relatively small number of family judges working in the Netherlands, it was simply not realistic to try and collect a sample of family judges equal to that of foster care workers. Study 1 and Study 2 also differed with respect to the instruments used in phase 2. Foster care workers conducted an online survey while family judges were interviewed. This decision was made because we found out that foster care workers had experienced technical problems with the online survey, which likely caused the eventually high rate of attrition. To prevent comparable challenges in the sample of family judges, we used a standardized face to face interview instead. 


\section{Discussion of Research Findings}

Four out of the five hypothesised clusters seemed to be indeed considered relevant for reunification by both foster care workers and/or family judges: 'birth parent's functioning and parenting skills', 'birth parent's acceptance of support', 'child's functioning, developmental needs and wishes', and 'foster-parent-child relationship'. Contrary to our expectations, one hypothesised cluster only seemed to be considered by foster care workers: 'birth parent-child relationship'. Furthermore, foster care workers considered two clusters that we did not hypothesise to appear as a cluster of information: 'readiness of the family' and 'preparation and timing adapted to the child'. In line with our hypothesis, the cluster that was perceived most important differed between the two groups of professionals.

Although, as expected, both foster care workers and family judges considered 'birth parent's acceptance of support' and 'child's functioning, developmental needs and wishes', in the exploratory concept maps these clusters of information were split up into two separate clusters. Both foster care workers and family judges separated criteria about the existence of formal and informal support from criteria about cooperation. Because the existence of formal and informal support seems to be a prerequisite for the possibility of parents to have a good collaboration with their support groups; by splitting it up into two clusters, the distinctive role of parents' acceptance of support becomes more apparent and can be clearly evaluated and judged (art. 1:255 lid 1 part a BW). Furthermore, contrary to foster care workers, family judges seem to discern criteria relating to the child's readiness for reunification from criteria about the child's functioning and wishes. Possibly, a family judge court perceives the child's functioning and wishes as a harbinger of his/her readiness, in such a way that family judges might first consider the child's functioning and wishes and use partly that information for informing about the readiness of the child.

In line with our expectations, family judges uniquely considered the foster parent-child relationship. This might be related to the different roles and responsibilities of the two groups of professionals in the reunification process. In the assessment of permanency planning, Dutch foster care workers frequently use instruments that do not include assessment of the foster parent-child relationship (Veenstra et al. 2014). Family judges however also have to take into account the child's current wellbeing in the foster family (Committee on the Right of the Children 2013) and foster parents' right to family life (art. 8 in European Court of Human Rights 2019).

Contrary to our expectations, foster care workers uniquely considered the 'secure birth-parent child relationship'. Although this cluster was not identified for the family judges, they did note several criteria regarding the birth parent-child relationship that were grouped under other clusters. This might indicate that family judges do not perceive birth parent-child relationship as a distinct construct in the way foster care workers do (Tilbury and Osmond 2006). Indeed, Dutch law does not mention the parent-child relationship as a separate focus of attention in the context of reunification, while parenting skills (art. 1:265d lid $1 \mathrm{BW}$ ) and child functioning (art. 1:255 lid $1 \mathrm{BW}$ ) are specifically mentioned and considered. This is in contrast with foster care workers, that consider the quality of the birth parent-child relationship as a unique construct, which might be based on attachment theory (Bowlby 1982).

Furthermore, there are two additional clusters of information that we did not expect being considered by foster care workers. The first is 'family readiness'. This cluster 
focused more on the entire family system than on individual members. Researchers have advocated ongoing ecological assessments to monitor whether the family is ready for reunification (Risley-Curtiss et al. 2004). Adopting a family-centred or -system approach seems to be more common in youth welfare practices currently. The second unexpected cluster is preparation and timing adapted to the child. This cluster contains criteria to be considered in the implementation of its outcome, reunification. This cluster was not expected because the inspected literature on permanency planning focuses on the choice for short- or long-term foster care; not on how the decision should be implemented (Schofield 2005; Tilbury and Osmond 2006). Yet, this finding is not surprising because one of the responsibilities of foster care workers is to actually prepare the child for reunification. For instance, by facilitating, intensifying and guiding the moments of parent-child contact (Children's Bureau 2013; Dutch Youth Institute 2013).

In line with our expectations we found a preliminary between-group difference regarding the cluster that is perceived most important. This concurs with an earlier study (Britner and Mossler 2002). Foster care workers seem to consider the birth parent-child relationship most important, whereas family judges regarded birth parents' functioning and parenting skills most important. To draw this conclusion with more certainty, future research ought to statistically test the differences of rated importance for the clusters of information within and between the two groups of professionals. Nevertheless, this result is in line with the observation that foster care workers consider attachment highly important in the context of permanency planning and decision making (Gauthier et al. 2004). Foster care workers observe the interactions and the relationship between parents and the child as part of their job (Daamen 2014). Indeed, the attachment relationship can have a profound impact on every aspect of the child's life (Tilbury and Osmond 2006). Family judges on the other hand, seem to regard birth parents' functioning and parenting skills most important, which was in line with the results of Vogels (2009). Given that judges have to follow the law, this finding was expected: Dutch law states that one of the reasons for out-of-home placement is that parents are not able to take care of their child (art. 1:265b BW). Thus, it seems likely that family judges consider the parents' abilities and functioning very important for making a decision to either or not terminate out-of-home placement.

The two exploratory concept maps can be used as a preliminary basis for a future conceptual framework or toolbox in decision-making on reunification. The clusters of information of the tools currently used by foster care workers in permanency planning in the Netherlands, lack specification in the sense that they do not include specific criteria (e.g. Choy and Schulze 2009). The concept map drawn in this study is an extensive overview of specific criteria that are part of a cluster of information. As such it may prove helpful for future permanency planning. For family judges, the concept map provides a summary of arguments deemed relevant in legal cases from 2011 till 2018. Although the concept maps and lists of criteria provide useful overviews and summaries that can help the process of decision making, it is important to note that these concept maps and lists of criteria should not be treated as evidence-base for criteria related to successful reunification because this was not tested in the current study.

Although there are some clusters of information considered by both foster care workers and family judges, clearly there are also clusters that have a more profession specific character. Considering the foster care workers' concept map could help family judges in being alert to the quality of decisions and the need to consider the implementation. Hence it might entice them to be more explicit in motivating their ruling and/or their reasons for not taking into account criteria that are considered paramount by foster care workers. By the same token, foster care workers can be encouraged to consider the criteria related to 
parenting and birth parents' functioning, presented in the concept map of family judges since these criteria are more extensive and detailed than the ones in the list of foster care workers (see "Appendices 2 and 4").

The differences in the perspectives could be problematic in decision-making practice, because it is likely that the groups of professionals do not have a shared vision regarding a case at the start of a court hearing. Misalignment can lead to mutual frustration (Vedder et al. 2015) and suboptimal implementation of court rulings by foster care workers. At the same time, disagreement between group of professionals can lead to fruitful discussion. Differences in the weight and use of criteria in a case by the different groups of professionals might lead to more critical and clearly argued decisions. However, disagreement is likely to lead to more fruitful discussions when different parties are aware of and appreciate these differences in perspective. The clusters of information appearing in this study may make family judges as well as foster care workers aware of possible (mis)alignment between the two groups of professionals. Therefore, it is important that during the court hearing the different groups of professionals try to understand each other's considerations and are willing and able to take these into account when coming to a judgement regarding family reunification. Gaining insight in the perspective of the other party may well prove to be a step forward in helping to reach alignment in the range of criteria that are being weighted in a discussion, because considerations can be addressed, challenged and transformed (Bronstein 2003). Therefore, it would be useful to include the exploratory study results in national guidelines, such as the Dutch "Guideline for out-of-home placement for child welfare" that is used by youth care professionals (NVO, BPSW and NIP 2015b).

\section{Directions for Future Studies}

Future research could look into the predictive power of the use of particular criteria or combinations of criteria for the ruling. This may help in assessing the validity of the findings in the current study. It may also shed more light on the importance of particular criteria and arguments or combinations of criteria in relation to a particular decision. Moreover, future research could look at the power of criteria or combinations of criteria used by family judges for predicting or explaining prolonged successful reunification or re-entry in the welfare system. Successful reunification is likely to be associated with a complex interplay of many factors.

Future studies could investigate more specifically which criteria are dynamic and can be influenced by intervention, and which criteria are unsusceptible to intervention. Additionally, future research could investigate the considerations of decision-making for family reunification in a broader model that is theoretically and empirically sound. For example, the decision-making ecology model includes a risk assessment including four criteria (Baumann et al. 2011). Adding the criteria found in this study to a theoretical model with organisational factors, external factors and decision maker factors can result in better understanding decision-making processes and their outcomes.

\section{Conclusions}

This study compared clusters of information that have been considered by foster care workers and family judges in decision-making on foster-child and birth family reunification. While there were similarities regarding the criteria and clusters that foster care workers 
and family judges considered, this study also identified differences. Since the nature of this research is exploratory and is based on small size samples, we have no clarity whether the results are representative of actual differences in the conceptual meaning of groups of criteria by foster care workers and family judges. These warrants caution. Nevertheless, the most surprising finding was that family judges seem not to perceive birth parent-child relationship as a distinct and independent construct in the way foster care workers do. Likely due to their different roles, expertise and responsibilities, the two groups of professionals adopt different perspectives and use different tools to argue their preferences, hesitations and decisions.

Not knowing about, or not understanding each other's perspective is likely to lead to mutual frustration and misalignment, it is also likely that insight into the reasoning or ruling by different parties can be helpful for systematic decision-making. By gaining more insight into other parties' perspective, it is a small but important step to better formalise and implement a decision in child welfare.

For future decision-making on reunification, the two concept maps from this study offers an overview of criteria used in previous legal cases and can be used to supplement foster care workers' current decision support tools. As such it provides a foundation for future studies that can eventually lead to the creation of evidence-based models that support evidence-based practices seeking to enhance the safety and wellbeing of foster-children.

Acknowledgements None.

Author's Contributions All authors contributed to the study conception and design. Material preparation and data collection were performed by Mirte Teunissen. Analyses were performed by Harold Nefs and Mirte Teunissen. The first draft of the manuscript was written by Mirte Teunissen and all authors commented on previous versions of the manuscript. All authors read and approved the final manuscript.

\section{Compliance with Ethical Standards}

Conflict of interest The authors declare that they have no conflict of interest.

Open Access This article is licensed under a Creative Commons Attribution 4.0 International License, which permits use, sharing, adaptation, distribution and reproduction in any medium or format, as long as you give appropriate credit to the original author(s) and the source, provide a link to the Creative Commons licence, and indicate if changes were made. The images or other third party material in this article are included in the article's Creative Commons licence, unless indicated otherwise in a credit line to the material. If material is not included in the article's Creative Commons licence and your intended use is not permitted by statutory regulation or exceeds the permitted use, you will need to obtain permission directly from the copyright holder. To view a copy of this licence, visit http://creativecommons.org/licenses/by/4.0/.

\section{Appendix 1: Dendrogram, CH-Index Plot and SSW Plot for Study 1}

See Figs. 3, 4, and 5. 


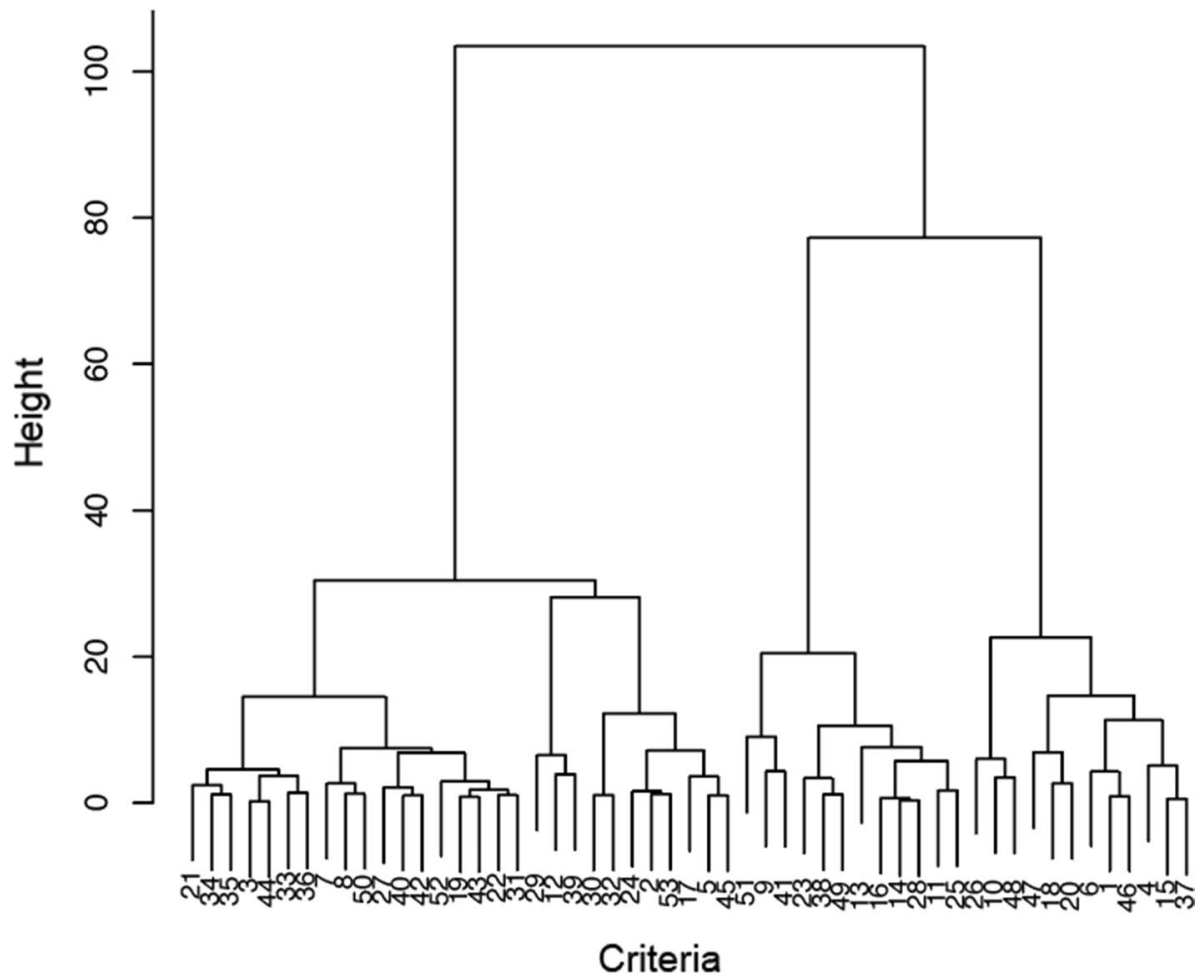

Fig. 3 Dendrogram: A visual clustering representation of foster care workers' decision-making criteria for Study 1 . The dashed line indicates a 7-cluster solution

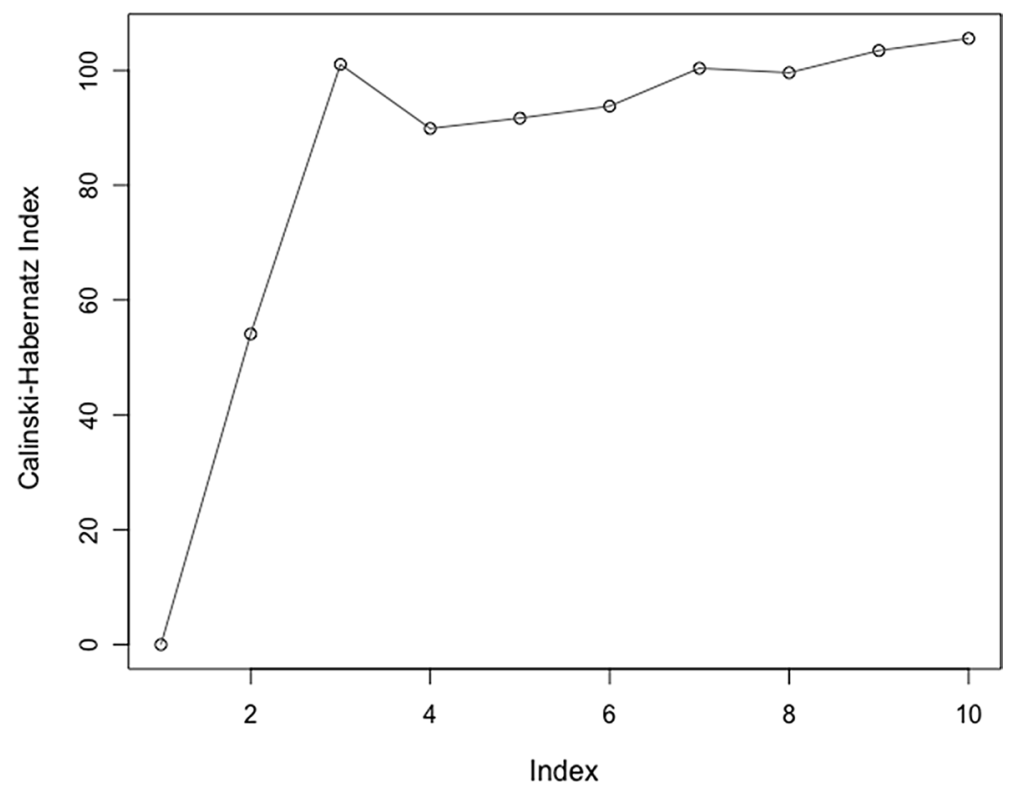

Fig. 4 CH-Index plot for Study 1 


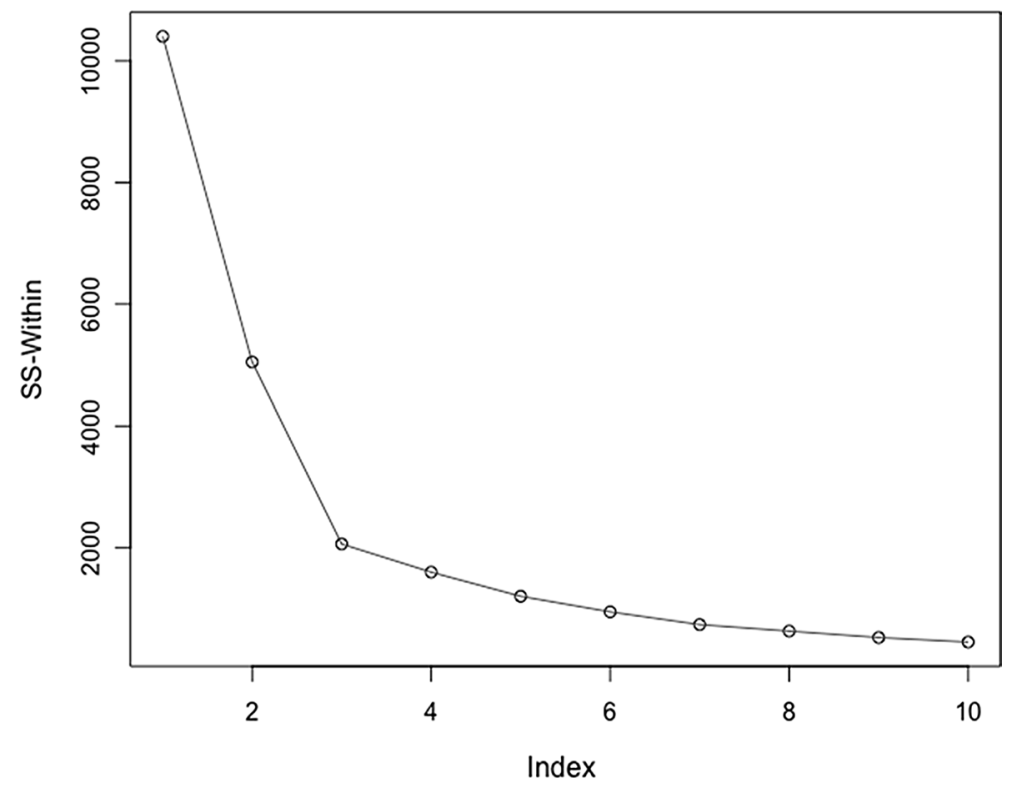

Fig. 5 SSW plot for Study 1

Appendix 2: Table Presentation of Criteria and Themes Used by Foster Care Workers for Study 1

See Table 3. 


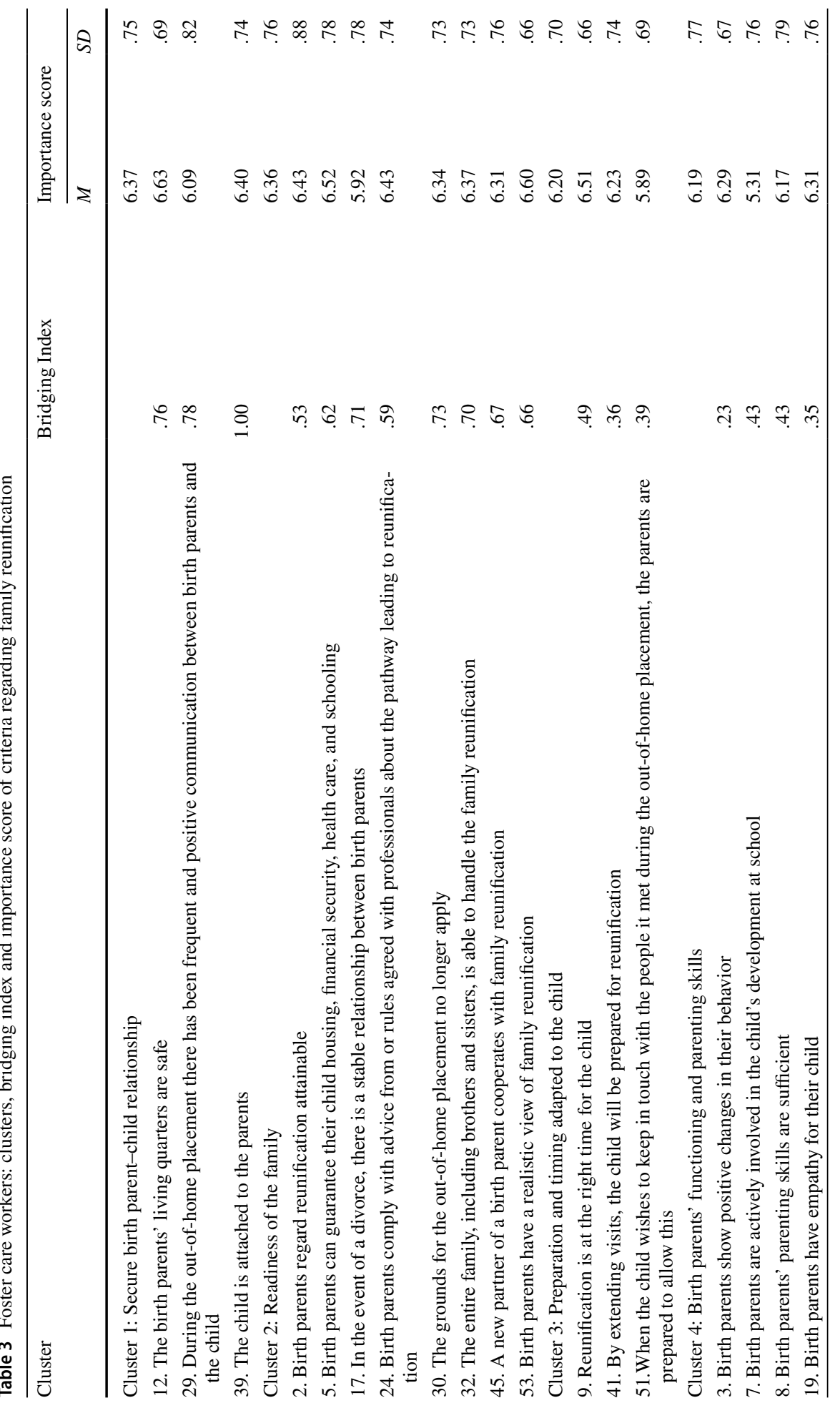




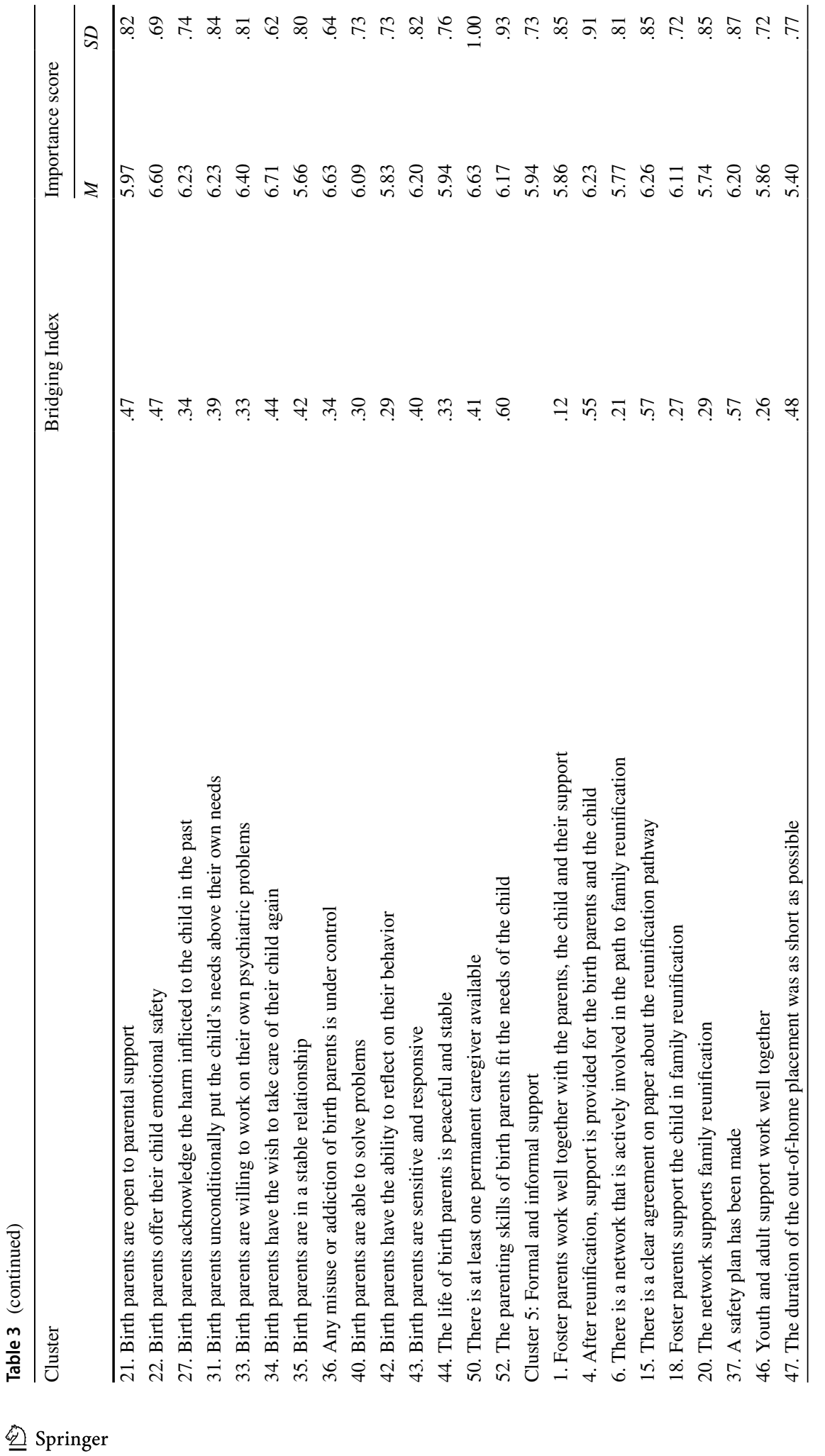




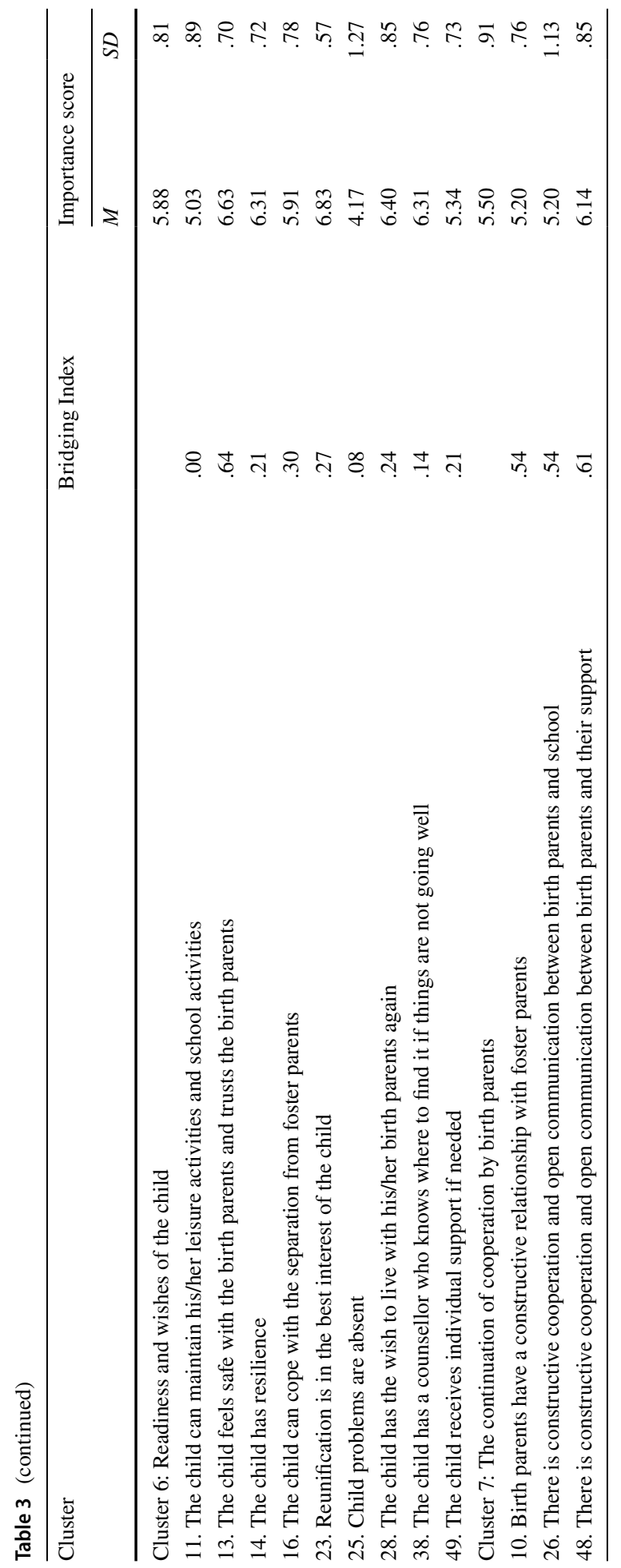




\section{Appendix 3: Dendrogram, CH-Index Plot and SSW Plot for Study 2}

See Figs. 6, 7, and 8 .

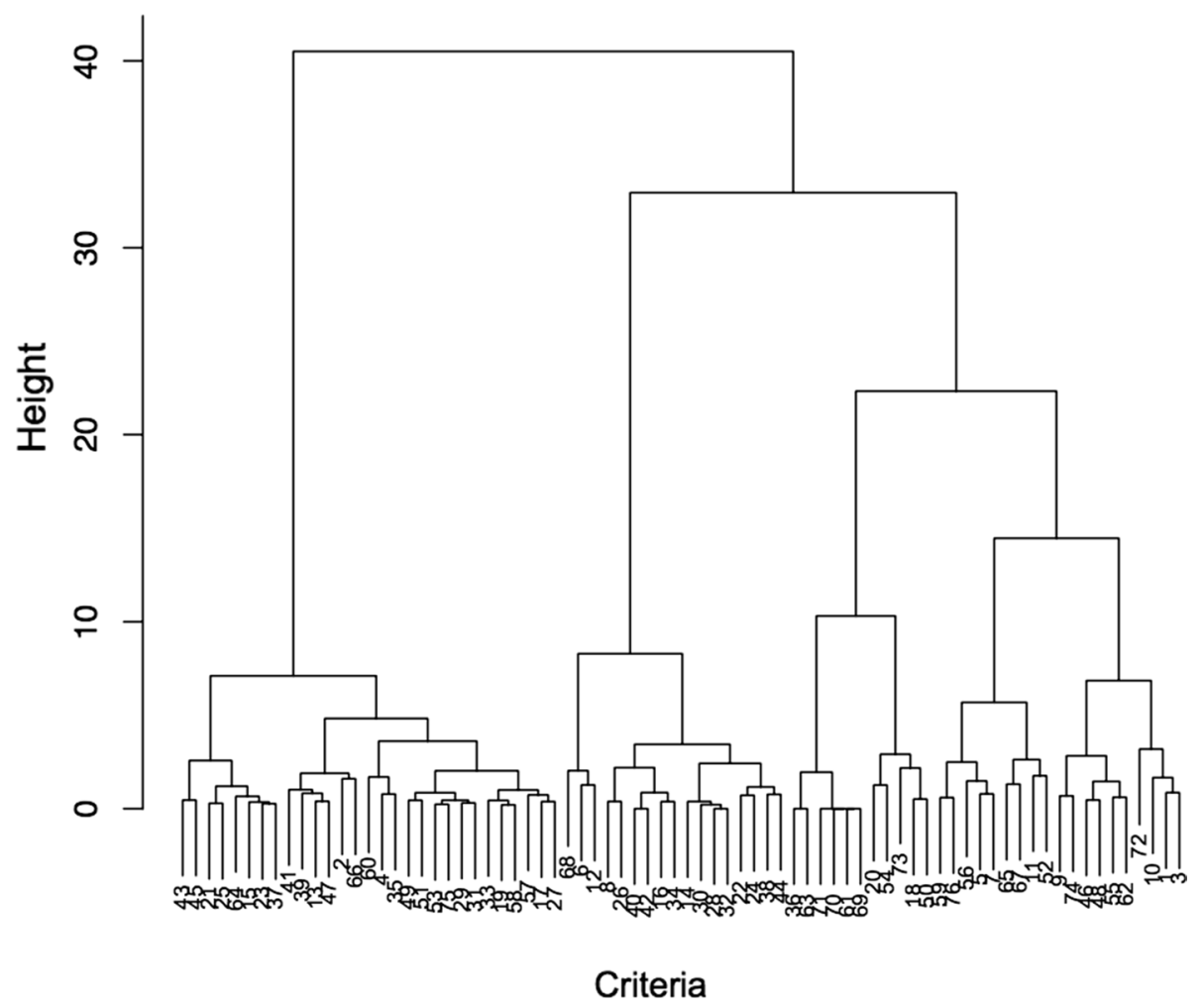

Fig. 6 Dendrogram: A visual clustering representation of family judges' decision-making criteria for Study 2. The dashed line indicates a 6-cluster solution 


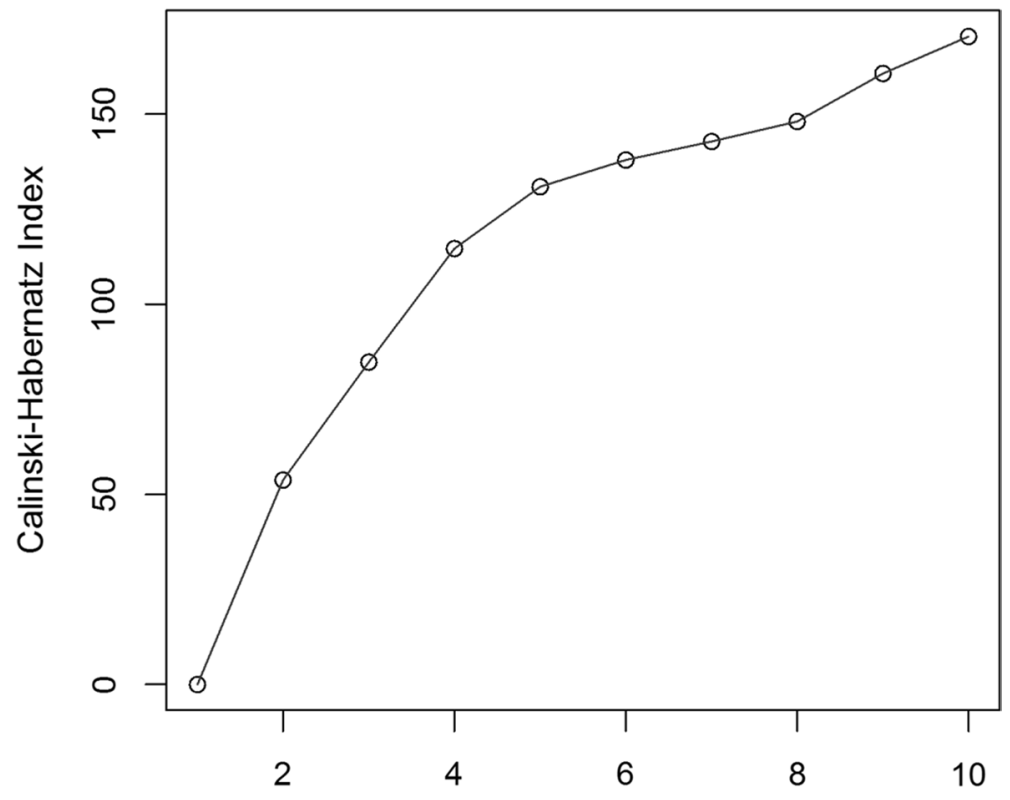

Fig. $7 \mathrm{CH}-$ Index plot for Study 2

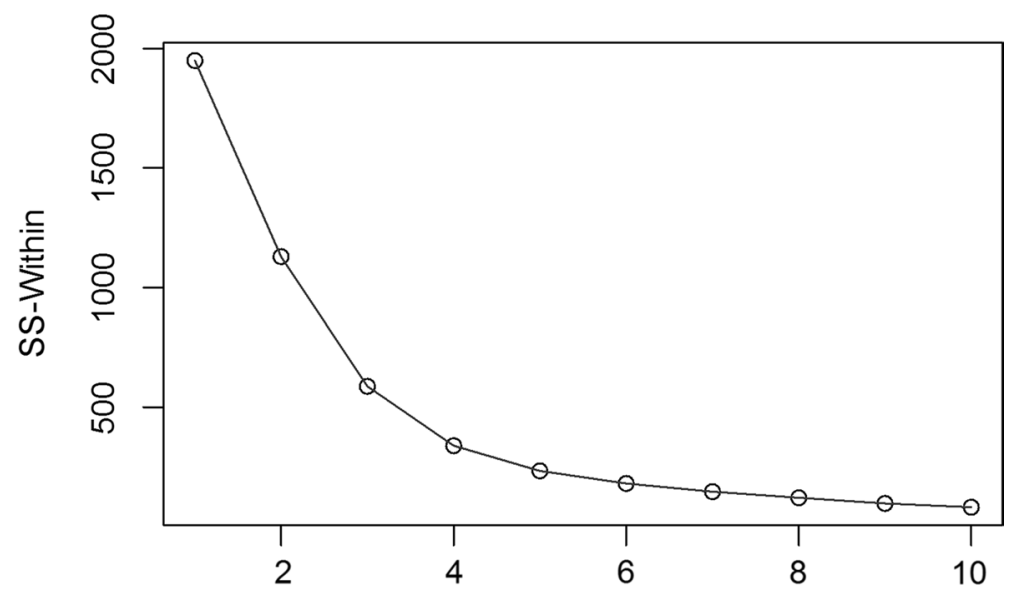

Fig. 8 SSW plot for Study 2

Appendix 4: Table Presentation of Criteria and Themes Used by Family Judges for Study 2

See Table 4. 


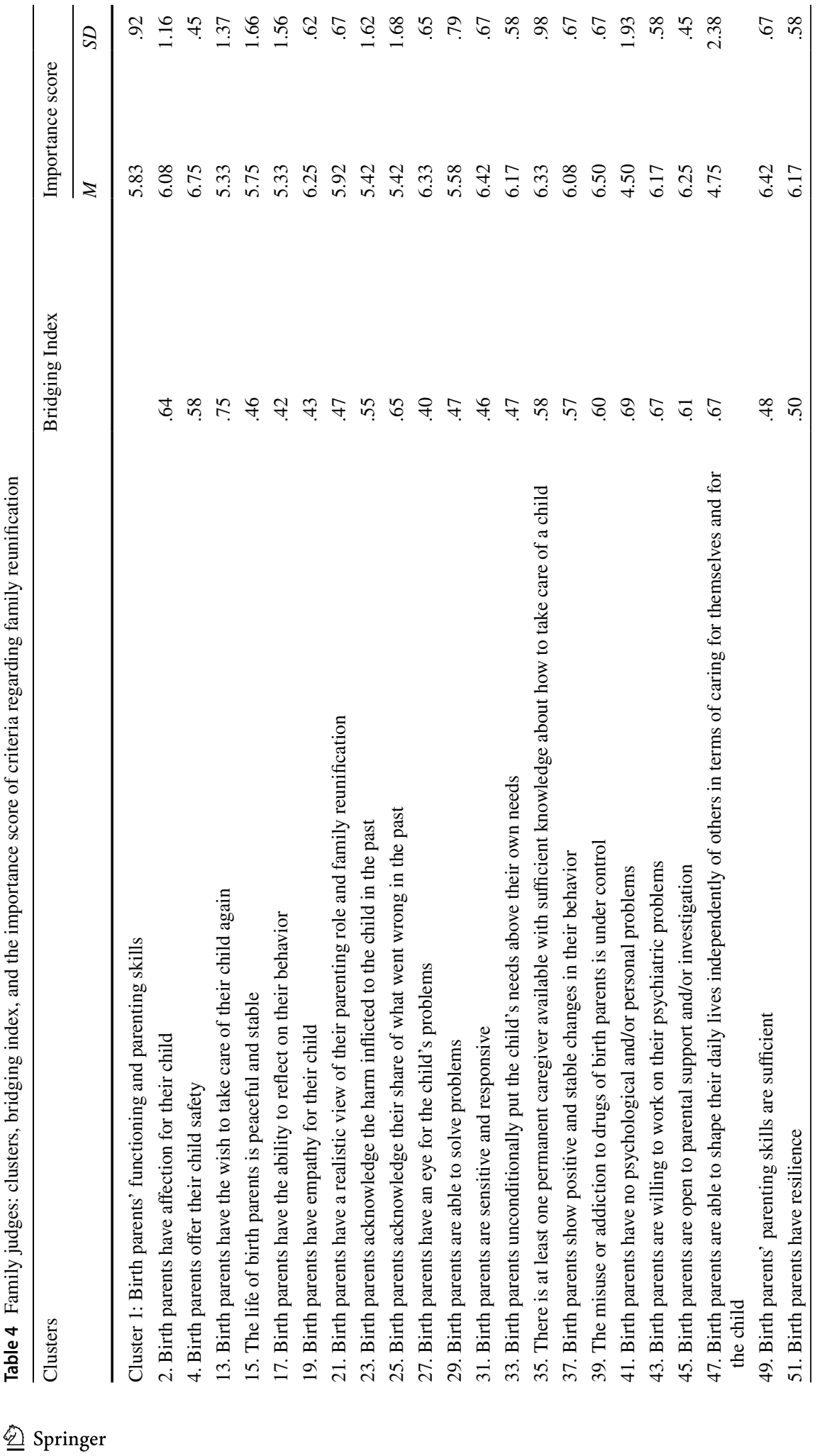




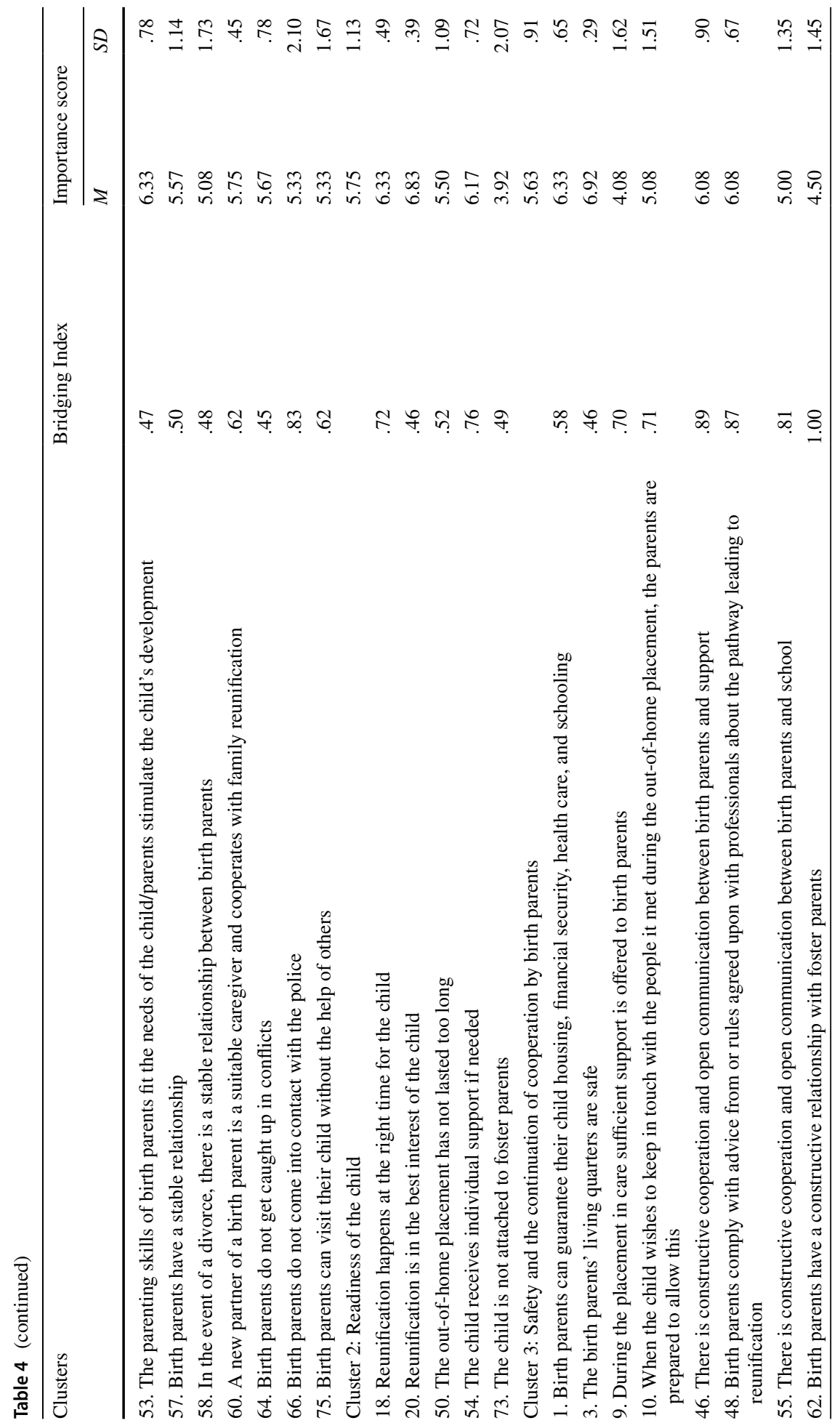




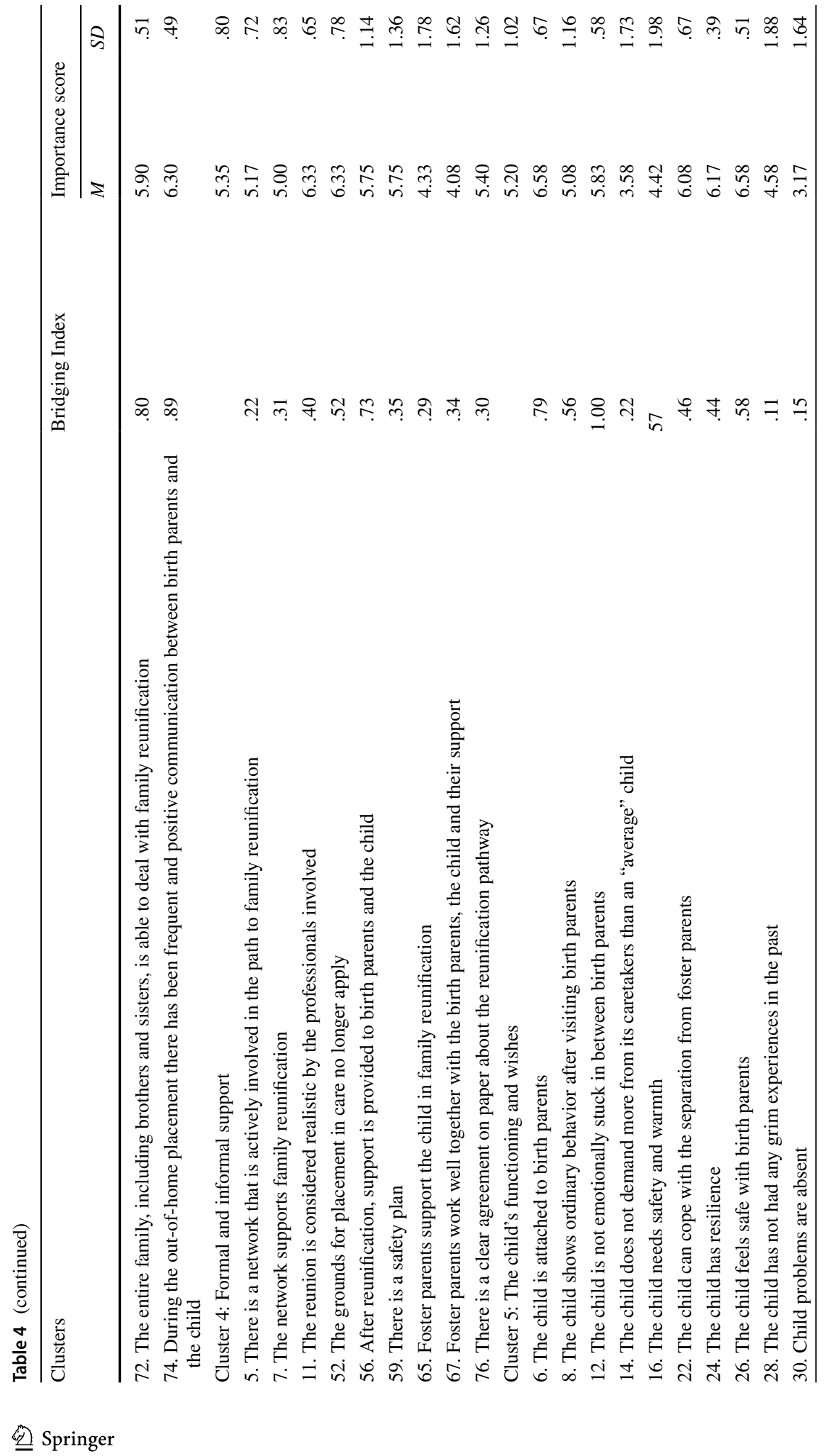




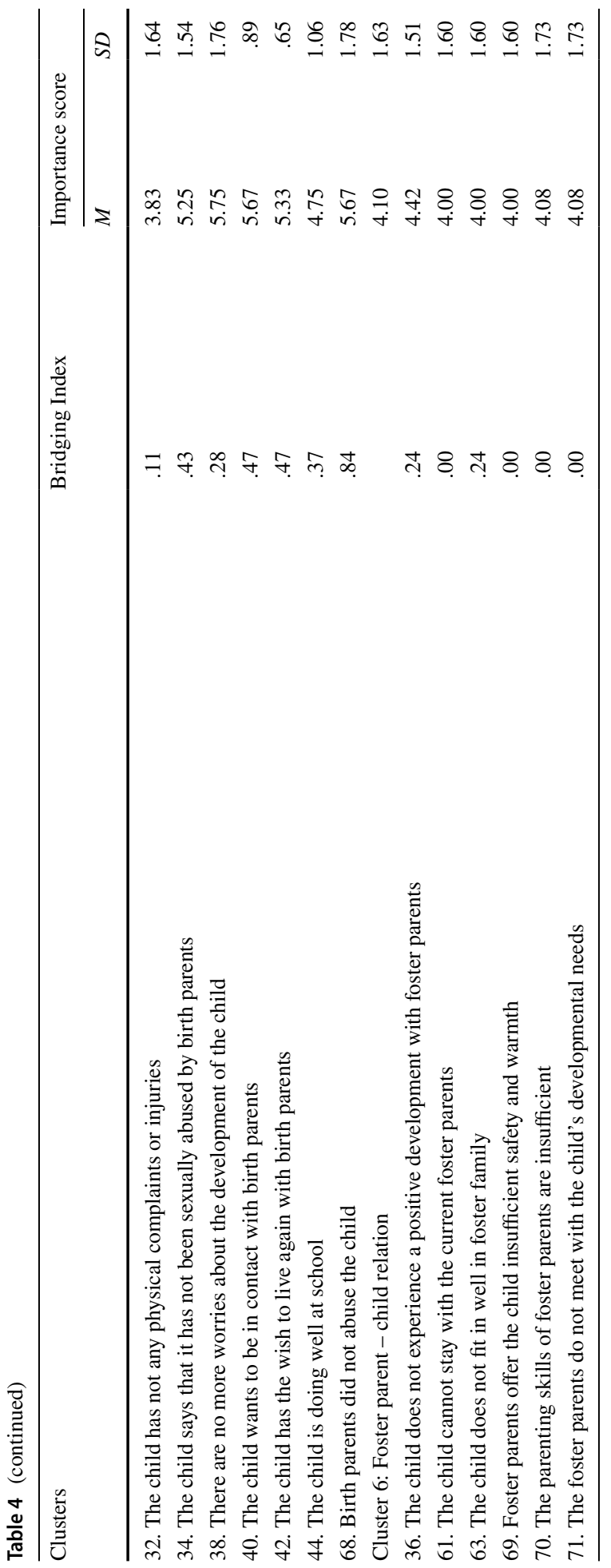




\section{Appendix 5: Adjustments in the List of Criteria of Family Judges}

We recommend that future studies incorporate the following five adjustments in the list of criteria of family judges:

1. the statement 'reunification was in the best interest of the child' was meant as a conclusion instead of an argument. Therefore, this statement can be left out the list.

2. the statement 'a child needs safety and warmth' was meant as a general principle instead of an argument. Therefore, this statement can be left out the list.

3. the statement 'a child demands more than an "average" child' was meant as additional information instead of an argument. Therefore, this statement can be left out the list.

4. the statement 'a child did not have any grim experience in the past' should preferably be stated as 'a child did not have experienced multiple changes of residence'. Therefore, this statement should be renamed.

5. the statement 'placement in care did not last too long' should preferably have been stated with a specific reference to the child's age. Therefore, this statement should be renamed.

\section{References}

Arad-Davidzon, B., \& Benbenishty, R. (2008). The role of workers' attitudes and parent and child wishes in child protection workers' assessments and recommendation regarding removal and reunification. Children and Youth Services Review, 30, 107-121. https://doi.org/10.1016/j.childyouth 2007.07.003.

Bartelink, C., Van Yperen, T., \& Ten Berge, I. J. (2015). Deciding on child maltreatment: A literature review on methods that improve decision-making. Child Abuse and Neglect, 49, 142-153. https:// doi.org/10.1016/j.chiabu.2015.07.002.

Baumann, D. J., Dalgleish, L., Fluke, J., \& Kern, H. (2011). The decision-making ecology. In A. Shlonksy \& R. Benbenishty (Eds.), From evidence to outcomes in child welfare (pp. 24-40). New York, NY: Oxford University Press.

Becker, A. M., Jordan, N., \& Larsen, R. (2007). Predictors of successful permanency planning and length of stay in foster care: The role of race, diagnosis and place of residence. Children and Youth Services Review, 29, 1102-1113. https://doi.org/10.1016/j.childyouth.2007.04.009.

Bowlby, J. (1982). Attachment and loss: Retrospect and prospect. American Journal of Orthopsychiatry, 52, 664-678. https://doi.org/10.1111/j.1939-0025.1982.tb01456.x.

Britner, P. A., \& Mossler, D. G. (2002). Professionals' decision-making about out-of-home placements following instances of child abuse. Child Abuse and Neglect, 26, 317-332. https://doi.org/10.1016/ S0145-2134(02)00311-3.

Bronstein, L. (2003). A model for interdisciplinary collaboration. Social Work, 48, 297-306. https://doi. org/10.1093/sw/48.3.297.

Brown, J. (2008). Foster parents' perceptions of factors needed for successful foster placements. Journal of Child and Family Studies, 17, 538-554. https://doi.org/10.1007/s10826-007-9172-z.

Children's Bureau. (2013). Preparing children and youth for adoption or other family permanency. Retrieved from https://www.childwelfare.gov/pubPDFs/preparing_youth.pdf.

Choy, J., \& Schulze, E. (2009). Kiezen voor kinderen: Een nieuwe blik op het samenspel in pleegzorg [Choosing for children: A new view on working together in foster care]. Amsterdam: Nisto Publications.

Committee on the Rights of the Children. (2013). General comment no. 14: On the right of the child to have his or her best interests taken as primary consideration (art. 3, §1). Retrieved from http:// www.refworld.org/docid/51a84b5e4.html.

Connell, C. M., Vanderploeg, J. F., Katz, K. H., Caron, C., Saunders, L., \& Tebes, J. K. (2009). Maltreatment following reunification: Predictors of subsequent Child Protection Services contact after children return home. Child Abuse and Neglect, 33, 218-228. https://doi.org/10.1016/j.chiab u.2008.07.005. 
Convention of the Rights of the Child. (1989). Preamble. Retrieved from https://www.ohchr.org/en/profe ssionalinterest/pages/crc.aspx.

Courtney, M. E. (1994). Factors associated with the reunification of foster children with their families. Social Service Review, 68, 81-108. https://doi.org/10.1086/604034.

Daamen, R. (2014). Begeleiden van pleegzorgouders: wat werkt? [Supporting foster care parents: What works?]. Retrieved from https://www.nji.nl/nl/Download-NJi/Publicatie-NJi/Review-Begeleiden -van-pleegouders-wat-werkt.pdf.

Dankaart, K. (2011). Besluitvorming en het beëindigen van pleeggezinplaatsingen [Decision making and terminating a foster care placement] (masterthesis). Leiden University Repository.

Dawson, K., \& Berry, M. (2002). Engaging families in child welfare services: An evidence-based approach to best practice. Child Welfare, 81, 293-317. Retrieved from https://www.researchga te.net/publication/11358090_Engaging_Families_in_Child_Welfare_Services_An_Evidence-Based _Approach_to_Best_Practice.

European Court of Human Rights, article 8. (2019). Guide on article 8 of the European Convention on Human Rights. Retrieved from https://www.echr.coe.int/Documents/Guide_Art_8_ENG.pdf.

Everitt, B. (1980). Cluster analysis (2nd ed.). New York, NY: Halsted Press.

Farmer, E. (2012). Improving reunification practice: Pathways home, progress and outcomes for children returning from care to their parents. British Journal of Social Work, 44, 348-366. https://doi. org/10.1093/bjsw/bcs093.

Farmer, E., \& Lutman, E. (2012). Effective working with neglected children and their families: Linking interventions to long-term outcomes. London: Jessica Kingsley Publishers.

Fuller, T. L. (2005). Child safety at reunification: A case-control study of maltreatment recurrence following return home from substitute care. Children and Youth Services Review, 27, 1293-1306. https://doi.org/10.1016/j.childyouth.2005.01.004.

Gauthier, Y., Fortin, G., \& Jéliu, G. (2004). Clinical application of attachment theory in permanency planning for children in foster care: The importance of continuity of care. Infant Mental Health Journal, 25, 379-396. https://doi.org/10.1002/imhj.20012.

Giguère, G. (2006). Collecting and analyzing data in multidimensional scaling experiments: A guide for psychologists using SPSS. Tutorial in Quantitative Methods for Psychology, 2, 26-37. https://doi. org/10.20982/tqmp.02.1.p026.

Goemans, A., Vanderfaeillie, J., Damen, H., Pijnenburg, H., \& Van Holen, F. (2016). Reunification of foster children: Factors associated with reunification outcomes in Flanders and the Netherlands. Children and Youth Services Review, 70, 284-291. https://doi.org/10.1016/j.childyouth .2016.09.023.

Jaworska, N., \& Chupetlovska-Anastasova, A. (2009). A review of multidimensional scaling (MDS) and its utility in various psychological domains. Tutorial in Quantitative Methods for Psychology, 5, 1-10. https://doi.org/10.20982/tqmp.05.1.p001.

Kruskal, J. B., \& Wish, M. (1978). Multidimensional scaling. Los Angeles, CA: Sage Publications.

López, M., Del Valle, J. F., Montserrat, C., \& Bravo, A. (2013). Factors associated with family reunification for children in foster care. Child and Family Work, 18, 226-236. https://doi.org/10.111 1/j.1365-2206.2012.00847.x.

Nederlands Jeugd instituut [Dutch Youth Institute]. (2013). Pleegzorgbegeleiding [Guidance in foster care]. Retrieved from https://www.nji.nl/nl/Download-NJi/Publicatie-NJi/Modulebeschrijving_ pleegzorgbegeleiding.pdf.

Nederlandse Gezinsraad [Dutch Family Council]. (2001). Thuisplaatsing van pleegkinderen: Een onderzoek naar de thuisplaatsing van pleegkinderen na langdurige uithuisplaatsing in het kader van ondertoezichtstelling [Family reunification of foster children: A study on reunification of foster children after out-of-home placement]. The Hague: ICB Publications.

Norman, R. E., Byambaa, M., De, R., Butchart, A., Scott, J., \& Vos, T. (2012). The long-term health consequences of child physical abuse, emotional abuse, and neglect: A systematic review and metaanalysis. PLOS Medicine, 9, 1-31. https://doi.org/10.1371/journal.pmed.1001349.

NVO, BPSW, \& NIP. (2015a). Richtlijn Pleegzorg [Guideline Family Foster Care]. Retrieved from http://richtlijnenjeugdhulp.nl.

NVO, BPSW, \& NIP. (2015b). Richtlijn Uithuisplaatsing voor jeugdhulp en jeugdbescherming [Guideline out-of-homeplacement for child welfare]. Retrieved from http://richtlijnenjeugdhulp.nl.

Risley-Curtiss, C., Stromwall, L. K., Hunt, D. T., \& Teska, J. (2004). Identifying and reducing barriers to reunification for seriously mentally ill parents involved in child welfare cases. Families in Society, 85, 107-118. https://doi.org/10.1606/1044-3894.240.

Schofield, G. (2005). The voice of the child in family placement decision-making: A developmental model. Adoption and Fostering, 29, 29-44. https://doi.org/10.1177/030857590502900105. 
Sinclair, I., Baker, C., Lee, J., \& Gibbs, I. (2007). The pursuit of permanency: A study of English childcare system. London: Jessica Kingsley Publishers.

Tilbury, C., \& Osmond, J. (2006). Permanency planning in foster care: A research review and guidelines for practitioners. Australian Social Work, 59, 265-280. https://doi.org/10.1080/03124070600833055.

Trochim, W. M. K. (1987). The concept system. Ithaca, NY: Trochim Publishing.

Trochim, W. M. K. (1989). An introduction to concept mapping for planning and evaluation. Evaluation and Program Planning, 12, 1-16. https://doi.org/10.1016/0149-7189(89)90016-5.

Vanderfaeillie, J., Van Holen, F., De Maeyer, S., Belenger, L., \& Gypen, L. (2017). Who returns home? Study on placement outcomes of Flemish foster children. Child and Family Social Work, 22, 503-515. https://doi.org/10.1111/cfs.12269.

Van Holen, F., Trogh, L., West, D., Meys, N., \& Vanderfaeillie, J. (2019). Concept mapping the needs of Flemish nonkinship foster parents who care for unaccompanied refugee minors. Children and Youth Services Review, 96, 84-92. https://doi.org/10.1016/j.childyouth.2018.11.043.

Vedder, P., Veenstra, M., Goemans, A., \& Van Geel, M. (2015). Perspectiefbepaling in de pleegzorg [Permanency planning in foster care]. Orthopedagogiek: Onderzoek en Praktijk, 54, 115-127. Retrieved from https://www.researchgate.net/publication/277590310_Perspectiefbepaling_in_de_pleegzorg.

Veenstra, M., Van Geel, M., Goemans, A., \& Vedder, P. (2014). Hoe wordt het perspectief van pleegkinderen in Nederland bepaald? Een inventarisatie en evaluatie van de gebruikte methodes [How is permanency planning arranged in the Netherlands? An inventory and evaluation of the methods used]. Retrieved from https://kennisnetjeugd.nl/?file=1803\&m=1414679435\&action=file.download.

Vial, A., Assink, M., Stams, G. J. J. M., \& Van der Put, C. (2020). Safety assessment in child welfare: A comparison of instruments. Children and Youth Services Review, 108, 1-18. https://doi.org/10.1016/j. childyouth.2019.104555.

Vischer, A. F., Grietens, H., Knorth, E. J., \& Mulder, H. (2017). Assessing parenting in the context of reunification of infants/toddlers and their families: How to face the challenges? Infant Mental Health Journal, 38, 406-421. https://doi.org/10.1002/imhj.21646.

Vogels, S. (2009). De beëindiging van uithuisplaatsing [Terminating the out-of-home placement] (masterthesis). Tilburg University Repository.

Wade, J., \& Biehal, N. (2011). Caring for abused and neglected children: Making the right decisions for reunification or long-term care. London: Jessica Kingsley Publishers.

Publisher's Note Springer Nature remains neutral with regard to jurisdictional claims in published maps and institutional affiliations.

\section{Affiliations}

\section{Mirte S. L. Teunissen ${ }^{1} \cdot$ Anouk Goemans $^{1}\left[\right.$ [ Frank van Holen ${ }^{2}$. Johan Vanderfaeillie ${ }^{2}$. Harold T. Nefs ${ }^{1} \cdot$ Huub M. Pijnenburg ${ }^{3} \cdot$ Harm Damen $^{4} \cdot$ Paul H. Vedder $^{1}$}

1 Institute of Education and Child Studies, Leiden University, Wassenaarseweg 52, 2333 AK Leiden, The Netherlands

2 Institute of Psychology, Vrije Universiteit Brussel, Brussels, Belgium

3 Praktikon Youth Care Research Centre, Nijmegen, The Netherlands

4 Pactum, Arnhem, The Netherlands 